\title{
The tolerance of English instructors towards the Thai-accented English and grammatical errors
}

\author{
Varisa Osatananda and Parichart Salarat* \\ Department of English, Faculty of Liberal Arts, Thammasat University, Khlong Luang, Pathum Thani, Thailand \\ Kasetsart University, 50 Thanon Ngamwongwan, Lat Yao, Chatuchak, Bangkok 10900, Thailand
}

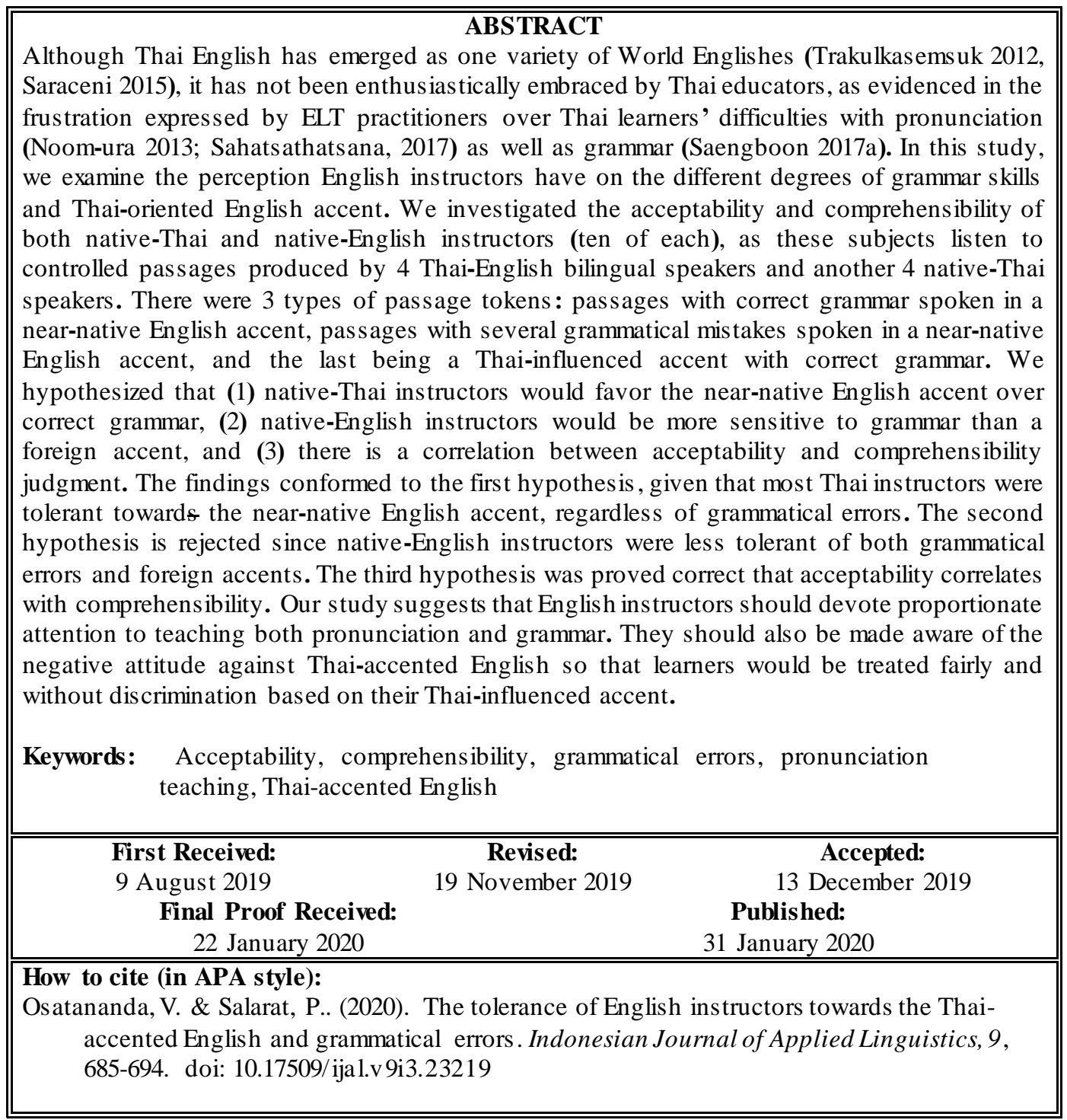

\section{INTRODUCTION}

Krashen (1982) posits that explicit instruction of language forms, or grammatical rules, is less effective than implicit instruction, which leads to learners' acquisition of grammatical knowledge. However, recent research indicates that explicit instruction is more effective than implicit instruction when teaching simple grammatical forms and complex ones such as dative alternation, question formation, relativization (Spada \& Tomita, 2010). On the other hand, Ling (2015) compares between explicit and implicit instruction of grammar in China and concludes that both teaching methods have their own strength. Both forms of instruction should be applied in the classroom to complement one another. 
The classroom situation in Thailand predominantly involves explicit grammar instruction and rote-learning (Punthumasen, 2007; Saengboon, 2017a). The lack of communicative classroom activities may have led to Thai students' low proficiency in English. Teachers, students, curricula, textbooks, and certain means of assessments are also to be blamed for the students' failure (Noom-Ura, 2013). In terms of grammar, Saengboon (2017a) points out problems with the low scores on grammar production and recognition tests, as performed by his MA student-participants. Despite the poor performance on the tests, his students strongly support explicit instruction of grammar because they believe that it helps them gain metalinguistic knowledge. Saengboon's findings highlight the necessity of incorporating grammar teaching into communicative teaching approaches. His viewpoint of explicit grammar instruction appears to have contradicted with students' perspectives taken from the previous research studies (Choomthong \& Chaichompoo, 2015; Punthumasen, 2007), which indicate that grammar has been a boring subject and has no benefits to their communicative skills.

Two decades ago, the so-called Communicative Language Teaching (CLT) approach was first promoted by Thailand's Ministry of Education in 1996 (Punthumasen, 2007). However, the traditional grammar-translation methods still prevail in some schools, as the teachers thought that CLT does not serve students' real needs to obtain high scores in the National Test (Promtara \& Suwannarak, 2018). Even though CLT has already been implemented in many schools and colleges, this approach has been misunderstood by students and sometimes misinterpreted by school teachers who thought that CLT involves merely listening-speaking skills when, in fact, CLT requires the practice of all four language skills: listening, speaking, reading, and writing (Promtara \& Suwannarak, 2018). Saengboon (2017b) points out that the challenges of CLT come from too much emphasis on the concept of Comprehensible Input Hypothesis while downplaying the explicit instruction of grammar. In other words, as much as CLT has been applied to English Language Teaching in educational institutions with high hopes that Thai students would make progress in the English language skills, the low scores from the various kinds of test including the negative feedback from the stakeholders have proved that a significant milestone for English Teaching and Learning has not been reached.

Although Richard (2006) clearly states that fluency is one of the goals of applying CLT in English teaching, he did not exclude pronunciation accuracy from the classroom activities. In fact, he suggests that activities that focus on both fluency and accuracy should be implemented. Still, CLT is viewed by some researchers (e.g., Thamarana, 2015) as an approach that puts too much emphasis on fluency hence lessens the importance of accurate pronunciation. Sasum and Weeks (2018) discussed the problems of Thai students' lack of English-speaking fluency without touching upon the issues of pronunciation. The prioritization of the CLT approach among ELT practitioners may not conform to their covert favoritism towards the nativeEnglish accent. Pinget (2011) conducted a rating experiment to examine the correlation between some prosodic properties and perceived fluency. The findings indicate that there is only a weak correlation between fluency and accent. This means that Thai learners, regardless of their communicative skill, may speak with a certain degree of Thai accent. The question is how many English instructors can tolerate students' speech utterances with Thai-influenced accents, henceforth Thai-accented English, even when no grammatical mistakes are detected. Our research aims at investigating the degree to which English-language instructors, both native-English, and native-Thai, can tolerate Thai-accented English when there are no grammatical mistakes in the message. We also examine the degree to which both groups of instructors can tolerate near-native English accent produced by Thai bilinguals, but with grammatical errors. The degree of tolerance is examined by means of two attitudinal dimensions: acceptability and comprehensibility. To carry out the investigation, a rating experiment has been conducted. We hypothesize that (1) native-Thai instructors would favor the native or near-native English accent over the correct grammar, (2) native-English instructors would tolerate the English spoken with correct grammar but with Thai-accented English more than the ones that sound near-native English, but with grammatical errors, and (3) acceptability level increases with the higher degree of comprehensibility; if an utterance is highly acceptable, it would be highly comprehensible and vice versa.

The answers to our research questions would enable us to conceptualize the instructors' attitude towards the Thai-oriented accent, which could lead to some pedagogical implications.

\section{English in Thailand}

Kachru's (1992) three well-known circles of English have been widely accepted as criteria for categorizing the type of Englishes spoken in each area. The countries which use English as a mother tongue are categorized as the inner circle. The outer circle includes those who use English as a second language. The expanding circle, lastly, consists of countries where English is considered to be a foreign language. Speakers of the expanding circle regard English varieties of the inner circle as their English model (Clement, 2011).

In Thailand, English has been taught and studied as a foreign language. This situates Thailand within the expanding circle (Rogers, 2013). English is currently a compulsory subject from Grade 1 onwards, and students are expected to be able to communicate in English as citizens of the ASEAN community (Rogers, 2013).

The status of Thai English as an English variety is far from being conclusive. While a few researchers view Thai English as an emerging variety of World Englishes (Saraceni, 2015; Trakulkasemsuk, 2012), others claim 
otherwise (Singhasak \& Methitham, 2016; Rogers, 2013). According to Bennui (2017), English spoken in Thailand belongs to Kachru's (2005) expanding circle, although he posits that there are sub-varieties of English spoken by Thai people: only a few Thais gain a command of Standard English while many others throughout the country speak broken English, namely 'Tinglish' or colloquial Thai English (Bennui, 2017). Baker (2012) has a similar view but with a caution that Thai English may have an overlapping status between the expanding circle and the outer one since English is also widely used as a lingua franca in Thailand. Whether or not the so-called Thai-English variety exists, English has long enjoyed its prestigious status as the most popular foreign language in Thai society for decades. The following statement from Punthumasen (2007, p. 3) is quite familiar among Thai people, "as Thailand has been independent and never colonized by the western countries, English is not the official language of the country."

This cliché has been commonly cited and repeated over and over as a legitimate excuse as to why Thai learners lack a sense of achievement in using English. It also reflects the status of English in Thailand as a foreign language or as a lingua franca at the international level, such as a member of ASEAN countries (Baker, 2012). This EFL pedagogical contexts result in Thai learners' favor towards the native-English accent while viewing the local Thai-influenced accent as problematic (Sahatsathatsana, 2017). An attitudinal study done by Jindapitak and Teo (2013) suggests that Thai learners of English favor the mainstream innercircle English accents such as British, American, or Australian, while their Thai-influenced accent is treated as unfavorable. Kanoksilapatham (2016) similarly reports that her university student-subjects view nativeEnglish pronunciation as a favorable accent. The desire to speak like native speakers of English is quite common in Thailand as well as other countries in which English is taught as a foreign language such as China (Jieyin, 2018), Malaysia (Teh \& Pilus, 2019) and Jordan (Alghazo \& Zidan, 2019).

Trakulkasemsuk (2012) outlines some broad components that embody the properties of Thai English. In terms of the phonetic features, the fricative sounds that do not exist in Thai; / $\mathrm{t} /, / \mathrm{J} /$, and $/ 3 /$ tend to be substituted by the sound $/ \mathrm{t} 6^{\mathrm{h}} /$ in Thai. The sounds $/ \mathrm{t} 6^{\mathrm{h}} /$, $/ \mathrm{t} /$, and /d/ in Thai are used for the English /dz/, / $/$ /, / / / respectively The sound $/ \mathrm{v} /$ does not exist in Thai either, and is replaced by /w/. Some of the problematic consonants in Trakulkasemsuk's list are similar to the findings from Bennui (2017), who studied English speeches of Thai tour guides along the Andaman Sea. Bennui (2017) raises the problems of the guides' articulation of consonant clusters: $/ \theta \mathrm{r} /$ is pronounced as $/ \mathrm{tr} /$, and several final consonant clusters are reduced to one consonant; for example, the words 'direct' (/-kt/), 'left' (/-ft/), and 'next' (/-kst/) become 'direk,' 'lef,' and 'neks' (Bennui, 2017). Trakulkasemsuk (2012) states that speakers of Thai English tend to pronounce the dichotomous lax/tense English vowels as short/long versions. In the same vein, the diphthongs /ei/ and /ov/ tend to be replaced by the long vowels /e:/ and /o:/ in Thai. At the suprasegmental level, Bennui (2017) reports that the data collected from his tour guides do not use the word stress in words like 'America,' or 'captain,' although they stressed all the syllables in words like 'separate' and 'centimeter.' He observed that some words were stressed at the final syllable, and many words were assigned the falling tone at the final position. Bennui's observation is similar to Isarankura's (2018) findings of the stress and tones in Thai that are transferred to English loanwords. She found that Thai students tend to assign the stress to the word-final position, pronouncing the syllable with a long vowel due to the negative transfer from Thai, which is a finalsyllable stressed language. Moreover, whenever the high tone in Thai is transferred to a syllable, it would sound as if that syllable is stressed. This means that if the high tone is assigned to an unstressed syllable, the word would sound incorrect. Although Isarankura's scope of the study is within English loanwords in Thai, her descriptions of the stress and tone assignment in the English loanwords are commonly detected in English utterances of Thai speakers.

It has been a traditional view that the components of language are vocabulary, morphology, phonology, syntax, and discourse. Saville-Troike (2009) suggests that the most important linguistic components to which learners should put the priority are vocabulary and syntax, followed by pronunciation. This view is in line with Trofimovich and Isaacs (2012). They state, "comprehensibility, which is by far the more important concept for achieving successful oral communication, is linked to grammar and vocabulary." (CBC News, 2012).

Linguistically speaking, the syntax is defined as "the study of the way in which phrases and sentences are structured out of words" (Radford, 2004, p. 1). Syntax and morphology are components of grammar. In this research, we hold the definition of the grammar defined by Saengboon (2017a, p. 23) as "basic and necessary linguistic elements." Khumphee and Yodkamlue (2017) found that the grammatical mistakes that are particular to Thai learners are punctuation, nouns, prepositions, verbs, and articles, respectively, while Syaripuddin (2015) investigates grammatical errors produced by Thai learners in both speaking and writing performance. She found that the common grammatical errors made by Thai learners are prepositions, questions, articles, plural form, subjectverb agreement, and tense (Syaripuddin, 2015)

The notion of intelligibility, comprehensibility, acceptability as well as accentedness come into play when one sets goals of teaching and learning grammar and pronunciation. Munro and Derwing (1995, p. 291) posited that intelligibility is "the extent to which an utterance is actually understood." Comprehensibility is defined as "listeners' perceptions of difficulty in understanding particular utterances." Accentedness directly corresponds to the judgment of one's speech. It 
assesses "how strong the talker's foreign accent is perceived to be." These 3 dimensions are related, although they are independent of one another.

Acceptability is a psychological dimension that is closely associated with the judgment of grammar. Szpyra-Kozlowska (as cited in Thomson, 2018) defines acceptability as a "degree of annoyance and irritability experienced by listeners." Many researchers make notes of the correlation between grammaticality and acceptability (Greenbaum, 1975; Manes, 1977; Poulsen, 2012, Ruivivar \& Collins, 2018), although a caution should be made that an acceptable sentence may not be grammatically correct; all things being equal, a correct sentence does not have to be acceptable. Crowther, Trofimovich, Isaacs, \& Saito, (2017), including Trofimovich and Isaacs (2012) state that the aims of teaching grammar are for comprehensibility, while Szpyra-Kozlowska (2014), Thomson (2018), and Ruivivar (2017) suggest that comprehensibility, as well as acceptability, are important dimensions for grammar teaching. On the other hand, the aims of teaching pronunciation have moved away from the native benchmark to the dimension of intelligibility (Kanoksilapatham, 2016; Saville-Troike, 2009), comprehensibility, awareness of various English accents, acceptability, and accentedness (Crowther et al., 2017; Thomson, 2018). Moedjito and Asrobi (2019) posit that intelligibility is the main aim of teaching pronunciation and that there are many factors that affect the degree of intelligibility; these are grammatical and lexical accuracy, word pronunciation, stress, adjustments in connected speech, intonation, rhythm, and fluency.

To summarize, the inner-circle varieties of English have long been enjoying their prestigious status as the preferable varieties to be taught in Thailand, although the target of English Teaching has been shifted to the dimensions of intelligibility, comprehensibility, and acceptability. These dimensions need to be considered as part of the goals for teaching grammar and pronunciation. In this research, we investigate the degree of acceptability and comprehensibility, where these two dimensions will be conflated to the notion of tolerance.

The word 'tolerance' in this study includes acceptability as defined by Szpyra-Kozlowska (2014) and comprehensibility by Munro and Derwing (1995), as mentioned above.

\section{METHOD}

Both quantitative and qualitative methods were used in this research. In terms of quantitative methodology, a rating-scale experiment was conducted in order to quantify the degree of acceptability and comprehensibility. Jesney (2004) points out that although there is a large number of rating experiments, the methods have been designed in different ways, depending on different research goals. For our research, we decided to follow the methods of comprehensibility ratings carried out by Derwing and Munro (1997),
Derwing and Rossister (2003), Munro and Derwing (1995a), Munro and Derwing (1995b), Munro and Derwing (1998), and as they show consistency with reference to the characteristics of raters (native vs. nonnative judges), the rating scales (9-point), the training of raters before the experimental session, and passage stimuli (text reading or story retelling). Moreover, a questionnaire was administered to all the raters in order to obtain qualitative data about how they think of teaching pronunciation and grammar. The details are as follows:

\section{Speakers}

Eight participants were asked to act as speakers: 4 ThaiEnglish bilinguals and 4 native-Thai students of English. Among them were 6 females and 2 males. All of them were born and raised in Thailand.

The Thai-English bilinguals were born and raised in ordinary Thai families. Three females are 26 years old, and one male is 25 years old. They speak Thai at home but have been exposed to the international English-speaking environment since their early years. All of them have an American-English oriented accent.

The native-Thai students enrolled in Thai schools since kindergarten. One male/female pair is 19 years old, while the other pair is 20 years old. They are currently studying at a university in Bangkok, and have never lived abroad.

\section{The passages to be read}

Passages were selected from Rogers (2017), Stempleski (2014), and White (2017) in which the difficulty is at the A2 level of CEFR. Such level was selected to be the source of text because it is one level below B1: an intermediate level whereby the Ministry of Education aims to have Thai high school graduates acquire (Sornkam, Person, \& Yordchim, 2018) The controlled passages were selected in order to minimize some irrelevant factors that might affect the rating, such as word choice and semantic accuracy. One passage is divided into 2 versions: one is with correct grammar, the other carries grammatical errors. The errors were based on Khumphee and Yodkamlue's (2017) and Syaripuddin's (2015) findings that pinpoint those that were commonly made by Thai students. There were 12 passage tokens in this experiment: each of the 4 ThaiEnglish bilinguals read 2 passages (4x2), and each of the 4 Thai speakers read one passage. Each passage consists of approximately 53 words. The ones with the grammatical errors carry an average of 11.75 errors or $22.17 \%$ of the passage.

Task for speakers

Four kinds of passage stimuli in this research study are:

1. Four passages; A1, B1, C1, and D1 (see Appendix I), with correct grammar spoken by 4 Thai-English bilingual speakers. The target constructs are near-native English accent and correct grammar.

2. Four passages as in (1) with grammatical errors; A2, B2, C2, and D1 spoken by the same 
Thai-English bilingual speakers. The target constructs are near-native English accent and grammatical errors.

3. Passages A1, B1, C1, and D1 spoken by 4 native-Thai speakers. The target constructs are Thai-accented English and correct grammar.

The Thai-English bilingual speakers were tasked with reading two identical English passages; one with no grammatical mistakes (A1, B1, C1, D1) and another one with grammatical errors (A2, B2, C2, D2), while the native-Thai speakers were asked to read only the passages with correct grammar (A1, B1, C1, D1).

\section{Recording}

During the recording, the speakers were asked to read each passage 3 times. The one with the best quality was selected as tokens for the rating. The recording device used was SONY (ICU-UX543F). The process took place in a quiet room at the homes of the English-Thai bilingual speakers. As for the Thai speakers, the recordings were done at one of the researchers' offices space. We randomized the order of the tokens to minimize the listeners' recognition of the speech utterances produced by the same speaker.

\section{Listener-raters}

Ten native-Thai instructors and 10 native-English instructors were requested to be listener-raters. They were different groups of listeners from those participated in our previous pilot study. All 20 of the instructors teach at a college level. For the Thai instructors, 8 are males, and 2 are females, with ages ranging from 31-40 years old (average 33.6, s.d. 3.565). From these 10 native-Thai instructors, 3 have PhDs, and 7 have an MA in Linguistics. For the 10 English instructors, there are 5 males and 5 females with ages that range from 31-63. Two of the native-English instructors have MAs, while the remaining 8 have Bas. The nationalities are as follows: 3 from the USA, 3 from England, 2 from Scotland, and 2 from Australia. Their length of residence in Thailand: 3-27 years (mean $=7.9$, s.d. 9.631).

\section{Rating sheet}

Listener-raters were given a 9-point scale rating sheet that requires them to assess acceptability and comprehensibility of the utterances they hear. The 9point scare was selected based on the recommended scale used in rating research (Jesney, 2004). The listener-raters confirmed with us that they understood the definition of these two constructs before the rating process began. However, the listener-raters were not informed that two passages, differentiated by the dichotomous variables between correct grammar and grammatical errors, were produced by the same speaker, nor were they informed of the two constructs under investigation; grammar and accentedness. This process was purposely done so that listener-raters are unaware of what constitutes each passage in order to avoid bias towards the voices they listened to. To familiarize out listener-raters with the assigned task, they were asked to listen to 2 speech samples produced by 2 other Thai speakers, one male, and one female, as a warm-up practice before the actual session starts. The listenerraters had 10 seconds between the speech intervals to decide on their rating scores. Once the audio session has started, they were not allowed to request for a replay of the passage tokens.

\section{Post-rating questionnaire}

In addition to the rating task given to the instructorparticipants, we also investigate the instructors' metalinguistic awareness of accentedness as well as the importance of grammar teaching. After the experiment session, the instructor-participants were given questions that directly ask their views about these issues through a Google Form. The questions were:

1. Compared between grammar and pronunciation, which is more important to you?

2. Is it acceptable that your students speak English with correct grammar, but with a Thai accent?

3. Is it acceptable that your students speak English with grammatical errors, but their accent is not difficult to understand?

4. In your English class, do you teach grammar more than pronunciation? Or vice versa?

\section{RESULTS}

1. The passage tokens with a near-native accent and correct grammar, produced by Thai-English bilingual speakers, were investigated for acceptability. We compared the rating results of native-Thai listener-raters and native-English listener-raters and found no statistical difference in the acceptability rating. That is, the utterances spoken by English-Thai bilingual speakers were highly accepted by both groups of listeners, as shown in the t-test results in Table 1.

Table 1. The comparison of acceptability rating for Thai-English bilingual speakers between native-Thai and native-English instructorraters: correct grammar

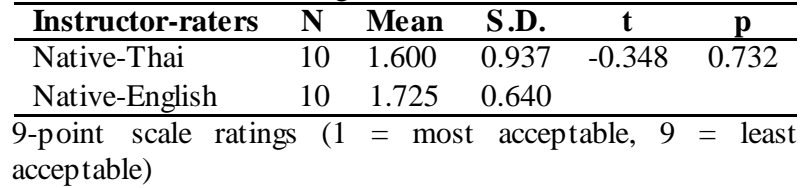

2. However, as shown in Table 2, in utterances that contained grammatical errors produced by ThaiEnglish bilingual speakers, Thai listeners highly accepted them (rating 1.750) while native-English listeners accepted them to a lesser degree (rating 3.975). The result indicates a statistical difference $(\mathrm{P}<.05)$ 
Table 2. The comparison of acceptability rating for Thai-English bilingual speakers between native-Thai and native-English instructorraters: grammatical errors

\begin{tabular}{lccccc}
\hline $\begin{array}{l}\text { Instructor- } \\
\text { raters }\end{array}$ & $\mathbf{N}$ & Mean & S.D. & $\mathbf{t}$ & $\mathbf{p}$ \\
\hline Native-Thai & 10 & 1.750 & 0.993 & -3.671 & $0.002^{*}$ \\
Native-English & 10 & 3.975 & 1.639 & & \\
\hline $\begin{array}{l}\text { 9-point scale ratings } \\
\text { acceptable })\end{array}$
\end{tabular}

3. As can be seen in Table 3, In rating comprehensibility for Thai-English bilinguals' utterances with correct grammar, both groups of listeners similarly felt that the utterances were highly comprehensible. In other words, the speech samples with correct grammar uttered by ThaiEnglish bilingual speakers were very easy to understand. There is no statistically significant difference in ratings between the two groups of listeners.

Table 3. The comparis on of comprehensibility rating for Thai-English bilingual speakers between native-Thai and native-English instructorraters: correct grammar

\begin{tabular}{lccccc}
\hline Instructor-raters & $\mathbf{N}$ & Mean & S.D. & $\mathbf{t}$ & $\mathbf{p}$ \\
\hline Native-Thai & 10 & 1.775 & 0.786 & 0.828 & 0.419 \\
Native-English & 10 & 1.500 & 0.697 & & \\
\hline $\begin{array}{l}\text { 9-point scale ratings } \\
\text { comprehensible) }\end{array}$
\end{tabular}

4. In rating the degree of comprehensibility of utterances with grammatical errors produced by Thai-English bilingual speakers, the Thai instructors felt that they were very easy to understand (rating 1.750), while native-English instructors felt that they were not as easy to understand, giving an average rating of 3.5 degrees of comprehensibility (see Table 4). The ratings between the two groups of listeners are statistically different at less than 0.05 level, as shown below:

5. We now turn to the result of rating the speeches of native-Thai speakers. Both groups of listeners deemed their speech utterances as fairly acceptable, even if they contained no grammatical errors. The passages were less acceptable for the native-English listener-raters. Nevertheless, the ratings of both groups do not show any significant differences, meaning that they all agree across the board, as seen in Table 5 .

Table 4. The comparis on of comprehensibility rating for Thai-English bilingual speakers between native-Thai and native-English instructorraters: grammatical errors

\begin{tabular}{lccccc}
\hline Instructor-raters & $\mathbf{N}$ & Mean & S.D. & $\mathbf{t}$ & $\mathbf{p}$ \\
\hline Native-Thai & 10 & 1.750 & 0.656 & -4.019 & $0.001^{*}$ \\
Native-English & 10 & 3.525 & 1.233 & & \\
\hline $\begin{array}{l}\text { 9-point scale ratings } \\
\text { comprehensible) }\end{array}$ & & & & & \\
\end{tabular}

Table 5. The comparison of acceptability rating for native-Thai speakers between native-Thai and native-English instructor-raters: correct grammar

\begin{tabular}{llllll}
\hline Instructor-raters & $\mathbf{N}$ & mean & S.D. & t & p \\
\hline Native-Thai & 10 & 4.350 & 1.281 & -1.337 & 0.198 \\
Native-English & 10 & 5.025 & 0.983 & & \\
\hline
\end{tabular}

9-point scale ratings $(1=$ most acceptable, $9=$ least acceptable)

6. Native-Thai, as well as native-English instructors, felt that the speech utterances produced by nativeThai speakers were moderately comprehensible (see Table 6). The native-English instructors found them slightly harder to understand than Thai instructors. The ratings are significantly different between the two groups.

Table 6. The comparis on of comprehensibility rating for native-Thai speakers between native-Thai and native-English instructor-raters: correct grammar

\begin{tabular}{llcccc}
\hline Instructor-raters & $\mathbf{N}$ & Mean & S.D. & t & p \\
\hline Native-Thai & 10 & 3.075 & 1.074 & -3.242 & $0.005^{*}$ \\
Native-English & 10 & 4.400 & 0.718 & &
\end{tabular}

9-point scale ratings $(1=$ most comprehensible, $9=$ least comprehensible)

To summarize the findings above, Table 7 shows the overall comparis on of the rating results between the two groups. According to Table 7, the similarities of the rating results between the two groups of listeners can be seen at the first and bottom rows. All the instructorraters agree that speech utterances with correct grammar produced by Thai-English bilingual speakers were highly acceptable and comprehensible, while the utterances produced by native-Thai speakers were much less acceptable and less comprehensible.

Table 7. Summary: the overall ratings of acceptability and comprehensibility rated by two groups of English instructors

\begin{tabular}{llrrrr}
\hline \multirow{2}{*}{ Speakers } & \multirow{2}{*}{ Type of utterances } & \multicolumn{2}{c}{ Acceptability } & \multicolumn{2}{c}{ Comprehensibility } \\
\cline { 3 - 6 } & & NT & NE & \multicolumn{1}{c}{ NT } & \multicolumn{1}{l}{ NE } \\
\hline Thai-English bilinguals & Correct gr. & 1.600 & 1.725 & 1.775 & 1.500 \\
& Gr. errors & $* 1.750$ & $* 3.975$ & $* 1.750$ & $* 3.525$ \\
Native-Thai & Correct gr & 4.350 & 5.025 & 3.075 & 4.400 \\
\hline
\end{tabular}

9-point scale ratings $(1=$ most acceptable, $9=$ least acceptable $)$

9-point scale ratings ( $1=$ most comprehensible, $9=$ least comprehensible)

NT $=$ Native-Thai instructor-raters, NE = Native-English instructor-raters

*significant difference between the two groups of listeners 
The significant difference lies in the middle row; while native-Thai instructors accepted the utterances with grammatical errors spoken by Thai-English bilingual speakers, native-English instructors found them less acceptable as well as less comprehensible.

A Pearson product-moment correlation coefficient was computed to assess the relationship between acceptability and comprehensibility. There was a positive correlation between the two variables, $r=.802$, $\mathrm{p}<.001$. The result indicates that there was a strong, positive correlation between acceptability and comprehensibility. That is, increases in degrees of acceptability were correlated with increases in degrees of comprehensibility. The result from our study seems to be in line with Ruivivar (2017), who states that learners with heavy foreign accents were perceived as second-language users with low grammaticality.

\section{Results from the questionnaire}

\section{Q1: Compared between grammar and pronunciation,} which is more important to you?

Both groups of listeners gave different responses. Many of them feel that grammar is more important (NT 3, NE 3 ), while others emphasize pronunciation (NT 3, NE 2). Some listeners talked about the ability to communicate as the most important aspect of language (NT 4, NE 5).

\section{Q2: Is it acceptable that your students speak English with correct grammar, but with a Thai accent?}

All the instructors gave a 'yes' response. Most of the comments tend to support the notions of intelligibility and comprehensibility, viewing that the goal of communication is to be able to comprehend the interlocutor's speech and, at the same time, make oneself understood by others. Some of them commented that as long as they understand the message, the accent should not be a problem.

\section{Q3: Is it acceptable that your students speak English with grammatical errors, but their accent is not difficult to understand?}

Most of the answers always begin with a "yes," followed by a "but" plus more explanation. For example, a native-Thai instructor said he could accept this as long as the communication is successful. Another Thai instructor said it is acceptable, although the articulation may sound strange. Native-English instructors have commented in the same direction as the native-Thai instructor group. They viewed that a comprehensible message is the most important aspect of communication.

\section{Q4: In your English class, do you teach grammar more than pronunciation? Or vice versa?}

The answers depend on the language course specific for each instructor. For example, a native-Thai instructor wrote that she taught grammar because she taught a translation class. However, most instructors admit that both subject areas are proportionately important. A native-English instructor wrote, "It would depend on the subject and the students' needs. Writing or a grammar class would focus heavily on grammar and less on pronunciation. A conversation class would need more balance" (NE1).

\section{DISCUSSION}

Our first hypothesis is that native-Thai instructors would favor the native or near-native English accent over the correct grammar. This hypothes is is confirmed. The result shows that native-Thai instructors accept the accent of Thai-English bilingual speakers, even when the utterances carry some grammatical errors. On the opposite, the passages produced in Thai-accented English were less acceptable and less comprehensible, although they contain no grammatical errors. The results, therefore, point to the favor towards the nativeEnglish voices, in accordance with the previous studies, which claim that Thai students prefer native-English models (Jindapitak \& Teo, 2013; Kanoksilapatham, 2016). There is no clear reason why native-Thai instructors accept near-native accent with grammatical errors. It is possible that some of them did not notice the errors. In order to find out, intelligibility should be tested by asking listeners to transcribe what they heard. However, since we did not test the intelligibility, it would be unfair to jump to the conclusion that they did not detect the mistakes. In light of this, another possible explanation could be that they truly prioritize the nearnative accent and that, unconsciously, grammatical errors are less important to them. On the other hand, the result indicates that native-Thai instructors rated less acceptability and comprehensibility in grammatically correct utterances produced by native-Thai speakers. The results from the experiment are not in line with their response in the questionnaire. That is when they were directly asked if it is acceptable to speak Thaiaccented English with correct grammar, all of them gave a 'yes' response. Because of this incongruity, we can conclude that their overt acceptance of Thaiaccented English with correct grammar does not conform to their covert attitude toward the localized Thai accent.

The second hypothesis posits that native-English instructors can tolerate the speeches produced with Thai-accented English and correct grammar, more than the ones that sound near-native but are produced with grammatical errors. This hypothesis is rejected. NativeEnglish instructors rated 5.025 for acceptability, and 4.400 for comprehensibility in the passages uttered by native-Thai speakers, in comparison with 3.975 ratings for acceptability and 3.525 for comprehensibility in rating the passages with errors uttered by Thai-English bilingual speakers, meaning that they barely tolerate the Thai-accented English, although the utterances contained no grammatical errors. As is the case with the response from the native-Thai instructors, when asked whether or not they could accept the Thai-accented English, all of the native-English instructors said that they did not mind if learners would speak English with a 
Thai accent, as long as the grammar was correct. It can be seen once again that the instructors' belief of foreign accentedness contradict with their unconscious attitude towards this discrepancy.

The findings above reflect that accentedness, in this case, Thai-accented English, exerts a significant influence on how instructors, whether English or Thai speakers, perceive English messages with a different degree of Thai-oriented accent. In an era when English is widely used not only between native-English (NE) speakers and non-native English (NNE) speakers, among the NNE speakers, pronunciation teaching with the goal of reaching the native or near-native accent has shifted to the issue of intelligibility (Jenkins, 2000, Kanoksilapatham, 2016; Moedjito \& Asrobi, 2019). Sewell (2016) points out that "rather than trying to make students sound like native speakers, the goal of pronunciation teaching is to enable them to be understood in a variety of contexts and style" (Sewell 2016, p. 89). However, the results from this study pedagogically imply that foreign-accent reduction is still compelling in English Language Teaching. And while the degree of foreign accent remains an important factor in assessing acceptability and comprehensibility, the degree of grammaticality, i.e., grammar correctness, is no less important, as the findings show that nativeEnglish instructors tolerate less in all passages containing grammatical mistakes. From this study, we found that grammatical mistakes in speech utterances are not acceptable, whether in near-native or Thaiaccented English, because no group of listeners was tolerant of the incorrect grammar. This might go against the current public view, which opens up to other varieties of English whose grammar may be different from those of inner circles. However, we have to keep in mind that the grammatical mistakes produced by Thai learners are treated as L2 errors, not the established grammar of an English variety. The fact that English utterances with grammatical mistakes are not acceptable is, therefore, not beyond our expectations in this regard. Trofimovich and Isaacs (2012) suggested that grammar and vocabulary are the most important dimensions that account for high comprehensibility. Their proposal remains true, considering that passages with grammatical errors were less acceptable and less comprehensible, regardless of the degree of accentedness.

Finally, our third hypothesis implies the correlation between acceptability and comprehensibility. If an utterance is highly acceptable by listeners, it should be automatically highly comprehensible. This hypothesis is confirmed, as we found the correlation between acceptability and comprehensibility. Myers (2017) posits that acceptability judgments primarily reflect language comprehension. The more a speech utterance is comprehensible, the more acceptable it would be to listeners and vice versa.

Burns (2019) emphasizes that there are 3 components of speaking competence that language teachers need to consider when teaching a speaking class: (1) knowledge of language and discourse, (2) core speaking skills, and (3) communication strategies. The first one includes knowledge of pronunciation, grammar, vocabulary, discourse, and genre (Burns, 2019). Our findings underscore the need to combine explicit instructions of pronunciation and grammar in language classes, particularly in the speaking classroom.

\section{CONCLUSION}

Although both native-Thai and native-English instructors claim that they accept a Thai-influenced English accent as long as it is comprehensible, in reality, they unconsciously have low tolerance towards such an accent even if it contains correct grammar. The findings point to an important role of explicit English pronunciation and grammar teaching. Our findings suggest that grammar and pronunciation should be given equal weight in English language teaching. A further question to be asked is on what aspects of pronunciation English instructors should focus on the Thai-classroom settings, based on the listeners' judgment of acceptability and comprehensibility. We are aware that in addition to the dichotomous errorfree/no-error grammar, phonetic factors such as the speech rates, pause, fluency, and the segmental nuances are accountable for the ratings. Unfortunately, these is sues are beyond our scope of the study. All in all, the outcomes of this study suggest that Thai instructors of English should be made aware of the fact that they may have a bias, whether hidden or disclosed, against Thaiaccented English in favor of the native/near-native one. Such bias may undermine grammar teaching and might lead to lower tolerance or even discrimination against learners with a strong foreign accent.

\section{REFERENCES}

Alghazo, S., \& Zidan, M. (2019). Native-speakerism and professional teacher in L2 pronunciation learning. Indonesian Journal of Applied Linguistics, 9(1), 241-251. doi: 10.17509/ijal.v9i1.12873

Baker, W. (2012). English as a lingua franca in Thailand: Characterisations and implications. Englishes in Practice: Working Papers of the Centre for Global Englishes. 1, 18-27.

Bennui, P. (2017). Speaking Tinglish for professional communication: A reflection of Thai English used by tourguides along the Andaman Sea. Silpakorn University Journal of Social Sciences, Humanities, and Arts, 17(3), 233-266. doi: $10.14456 /$ sujsha. 2017.30

Burns, A. (2019). Concepts for teaching speaking in the English language classroom. LEARN Journal: Language Education and Acquisition Research Network Journal, 12(1), 1-11.

Clement, K. (2011). The world Englishes paradigm and its implications for international students' acquisition of standard American English for 
university-level studies in the United States (Master's thesis, Minnesota State University, Minnesota, USA). Retrieved from https://corners tone.lib.mnsu.edu/etds/272/

Choomthong, D., \& Chaichompoo, C. (2015). English language learning motivation of Thai undergraduate students in the globalized era. Suranaree Journal of Social Science, 9(2), 23-45.

Crowther, D., Trofimovich, P., Isaacs, T., \& Saito, K.

(2017). Linguistic dimensions of second language accentedness and comprehensibility vary across speaking tasks. Studies in Second Language Acquisition, 40(2), 443-457. doi: 10.1017/S027226311700016X

Derwing, T. M., \& M. J. Munro (1997). Accent, intelligibility, and comprehensibility: Evidence from four L1s. Studies in Second Language Acquisition, 19, 1-16.

Derwing, T. M., \& M. J. Rossiter (2003). The effects of pronunciation instruction on the accuracy, fluency, and complexity of L2-accented speech. Applied Language Learning, 13, 1-18.

Greenbaum, S. (1975). Language variation and acceptability. TESOL Quarterly, 9(2), 165-172.

Is arankura, S. (2018). The effects of stress and tones in Thai on the pronunciation of English polysyllabic loanwords among Thai EFL students. Language, Education, and Acquisition Research Network Journal, 11(2), 66-83.

Jenkins, J. (2000). The phonology of English as an international language. Oxford, England: Oxford University Press.

Jesney, K. (2004). The use of global foreign accent rating in studies of $L 2$ acquisition. Calgary: University of Calgary Language Research Centre Reports.

Jieyin, L. (2018). A study of students' preferences towards native and non-native English teachers at Guangxi University of Finance and Economics, China. Language, Education, and Acquisition Research Network Journal, 11(2), 134-147.

Jindapitak, N., \& Teo, A. (2013). Accent priority in a Thai university context: A common sense revisited. English Language Teaching, 6(9), 193204. doi: 10.5539/elt.v6n9p 193

Kachru, B. B. (1992). Models for non-native Englishes. In B. B. Kachru (Ed.), The Other Tongue (pp. 4874). Urbana, IL: University of Illinois.

Kachru, B. B. (2005). Asian Englishes: Beyond the canon. Hong Kong: Hong Kong University Press .

Kanoksilapatham, B. (2016). Towards global English horizons. Language, Education, and Acquisition Research Network Journal, 9(2), 44-48.

Khamprated, N. (2012). The problems with the English listening and speaking of students studying at a private vocational school. (Master's Thesis, Srinakharinwirot University, Bangkok, Thailand). Retrieved from http://thesis.swu.ac.th/swuthesis/Tea_Eng_For_an( M.A.)/Nualsri_K.pdf
Khumphee, S., \& Yodkamlue, B. (2017). Grammatical errors in English essays written by Thai EFL undergraduate students. Journal of Education, Mahasarakham University, 11(4), 139-154.

Krashen, S. (1982). Principle and practice in second language acquisition. Oxford, England: Pergamon.

Ling, Z. (2015). Explicit grammar and implicit grammar teaching for English major students in university. Sino-US English Teaching, 12(8), 556-560. doi: 10.17265/15398072/2015.08.002

Manes, J. (1977). Acceptability in language. In S. Greenbaum (Ed.), Contributions to the Sociology of Language, New York: Mouton Publishers.

Moedjito, S. R. J., Jaelani, S. R., \& Asrobi, M. (2019). What makes EFL speakers' utterances more intelligible in the context of global intelligibility? Indonesian Journal of Applied Linguistics, 9(1), 157-166. doi: 10.17509/ijal.v 9i1.15235

Munro, M. J., \& Derwing, T. M. (1995b). Foreign accent, comprehensibility, and intelligibility in the speech of second language learners. Language Learning, 45(1), 73-97. doi: 10.1111/j.14671770.1995.tb00963.x

Munro, M. J., \& Derwing, T. M. (1995b). Processing time, accent, and comprehensibility in the perception of native and foreign-accented speech. Language and Speech,38(3), 289-306. doi: $10.1177 / 002383099503800305$

Myers, J. (2017). Acceptability judgment. Oxford Research Encyclopedia of Linguistics. doi: 10.1093/acrefore/9780199384655.013.333

Noom-Ura, S. (2013). English-teaching problems in Thailand and Thai teachers' professional development needs. English Language Teaching, 6(11), 139-147. doi: 10.5539/elt.v6n11p139.

Poor grammar, not accents, lead to misunderstanding. (2012, October 3). CBC News. Retrieved from https://www.cbc.ca/news/technology/poorgrammar-not-accents-lead-to-misunderstanding1.1255059

Pinget, A-F. (2011). Native speakers' perceptions of fluency and accent in L2 speech. (Unpublished Master Thesis). Utrecht University.

Poulsen, M. (2012). The usefulness of the grammaticality-acceptability distinction in functional approaches to language. Acta Linguistica Hafniensia, 44(1), 4-21. doi: 10.1080/03740463.2011.735472.

Promtara, N., \& Suwannarak, K. (2018). Thai students and teachers 'perceptions of learning and teaching English through the communicative language teaching approach. NIDA Journal of Language and Communication, 23(33), 23-42.

Punthumasen, P. (2007). International programfor teacher education: An approach to tackling problems of English education in Thailand. Paper presented at the $11^{\text {th }}$ UNESCO-APEID International Conference Reinventing Higher Education: Toward Participatory and Sustainable Development, Bangkok, Thailand. 
Radford, A. (2004). English syntax: An introduction. Cambridge, England: Cambridge University Press.

Richards, J. C. (2006). Communicative language teaching today. New York, NY: Cambridge University Press.

Rogers, U. (2013). Thai English as a variety. (Doctoral dis sertation, Arizona State University, Arizona, USA). Retrieved from https://repository.asu.edu/attachments/110689/cont ent/Rogers_asu_0010E_13107.pdf

Rogers, L. (2017). Personal best: A2 elementary student's book. Oxford, England: Richmond.

Ruivivar, J. (2017). Gotta speak real English: Foreign accent and L1 speakers' perceptions of nonstandard grammar. (Master's Thesis, Concordia University, Quebec, Canada). Retrieved from

https://spectrum.library.concordia.ca/982223/1/Rui vivar_MA_S2017.pdf

Ruivivar, J., \& Collins, L. (2018). The effect of foreign accent on perceptions of nonstandard grammar: A pilot study.TESOL Quarterly, 52(1), 187-198. doi: $10.1002 /$ tesq. 374

Saengboon, S. (2017a). English grammar and Thai university students: An insurmountable linguistic battle? English Language Teaching , 10(11), 22-36. doi: $10.5539 /$ elt.v10n $11 \mathrm{p} 22$

Saengboon, S. (2017b). Teaching wisdom of awardwinning teachers: A case study of Thai EFL teachers. NIDA Case Research Journal, 9(2), 1844.

Sahatsathatsana, S. (2017). Pronunciation problems of Thai students learning English Phonetics: A case study at Kalas in University. Journal of Education, Mahasarakham University, 11(4), 67-84.

Saraceni, M. (2015). World Englishes: A critical analysis. London, England: Blooms bury Academic.

Sasum, S., \& Weeks, B. (2018). Why some Thai students cannot speak English fluently? Paper presented at the third RSU International Research Conference 2018 (pp. 361-367). Pathumthani, Thailand.

Saville-Troike, M. (2009). Introducing second language acquisition. Cambridge, England: Cambridge University Press.

Sewell, A. (2016). English pronunciation models in a globalized world: Accent, acceptability, and Hong Kong English. Oxon, England: Routledge.
Singhasak, P., \& Methitham, P. (2016). Non-native English varieties: Thainess in English narratives. English Language Teaching, 9(4), 128-138. doi: 10.5539/elt.v9n4p 128

Sornkam, B, Person, K. R., \& Yordchim. S. (2018, November). Reviewing the Common European Framework of Reference for English Language in Thailand higher education. Paper presented at Graduate School Conference, Bangkok, Thailand. Spada, N., \& Tomita, Y. (2010). Review article: Interactions between type of instruction and type of language feature: A Meta-Analysis. Language Learning, 60(2), 263-308. doi: 10.1111/j.14679922.2010.00562.x

Stempleski, S. (2014). Stretch MULTI-PACK $2 A$. Oxford, England: Oxford University Press.

Syaripuddin, A. B. (2015). Grammatical error analys is in Thai students' English writing and speaking at UIN Alauddin Makassar. ETERNAL (English, Teaching, Learning, and Research Journal), 1(1), 57-68. doi: 10.24252/Eternal.V11.2015.A8

Szpyra-Kozlowska, J. (2014). Pronunciation in EFL instruction: A Research-Based Approach. Journal of Academic Language \& Learning, 9(1), B1-B3.

Teh, J. L., \& Pilus, Z. (2019). International students' perspectives of Malaysian English teachers' spoken English. Indonesian Journal of Applied Linguistics, 8(3), 555-566. doi: 10.17509/ijal.v8i3.15255

Thamarana, S. (2015). A critical overview of communicative language teaching. International Journal of English Language, Literature and Humanities, 3(5), 90-100.

Thoms on, R. I. (2018). Measurement of accentedness, intelligibility and comprehensibility. In O. Kang \& A. Ginther (Eds.), Assessment in second language pronunciation (pp. 11-29). New York: Routledge.

Trakulkasemsuk, W. (2012). Thai English: An emerging variety of world Englishes. In E.-L. Low \& A. Hashim, (Eds.), English in Southeast Asia: Features, policy and language in us (pp. 101-111). Joh Benjamins.

Trofimovich, P., \& Isaacs, T. (2012). Disentangling accent from comprehensibility. Bilingualism: Language and Cognition, 15, 905-916. doi: $10.1017 /$ S1366728912000168 